\title{
La narrativa de la desesperanza: El embarcadero de los incurables (1998) de Fernando Cruz Kronfly*
}

Fecha de recepción: 26 de septiembre de 2014

Fecha de aprobación: 15 de abril de 2015

\section{Resumen}

Antes de entrar en algunos detalles de la novela El embarcadero de los incurables (1998), a través del problema de la desesperanza, este artículo busca, primero, articular esta novela a una tradición narrativa y, luego, ubicarla en el conjunto de la obra de Fernando Cruz Kronfly. En términos generales el problema y su expresión novelesca son entendidos como una evaluación estética de la crisis de la modernidad y sus valores, así como una toma de posición frente a los asaltos del sentir y el modo posmoderno de vida. A manera de ejemplo, haciendo énfasis en el tipo de novela practicado por el autor, en esta se analiza la condición de los sujetos de hoy y su intrascendencia en las urbes posmodernas.

Palabras clave: desesperanza, Fernando Cruz Kronfly, novela, modernidad, posmodernidad

* Artículo de reflexión

Citar: Padilla Chasing I. V. (julio-diciembre de 2015). La narrativa de la desesperanza: El embarcadero de los incurables (1998) de Fernando Cruz Kronfly. La palabra, (27), $47-66$.
Iván Vicente Padilla Chasing Profesor asociado Universidad Nacional de Colombia ivpadillac@unal.edu.co 


\section{The narrative of despair: El embarcadero de los incurables [The pier of the incurables] (1998) by Fernando Cruz Kronfly}

\section{Abstract}

Before going into some details of the novel El embarcadero de los incurables [Thepier of the incurables] (1998), through the issue of despair, this article seeks, first, to articulate this novel a narrative tradition and then place it in the whole work Fernando Cruz Kronfly. In general terms the problem and its romantic expression are understood as an aesthetic assessment of the crisis of modernity and its values, as well as taking a position against the assaults of feeling and the postmodern way of life. By way of example, with emphasis on novel type practiced by the author, in this condition the subjects of today and its insignificance in postmodern cities are analyzed.

Keywords: despair/hopelessness, Fernando Cruz Kronfly, novel, modernity, postmodernism.

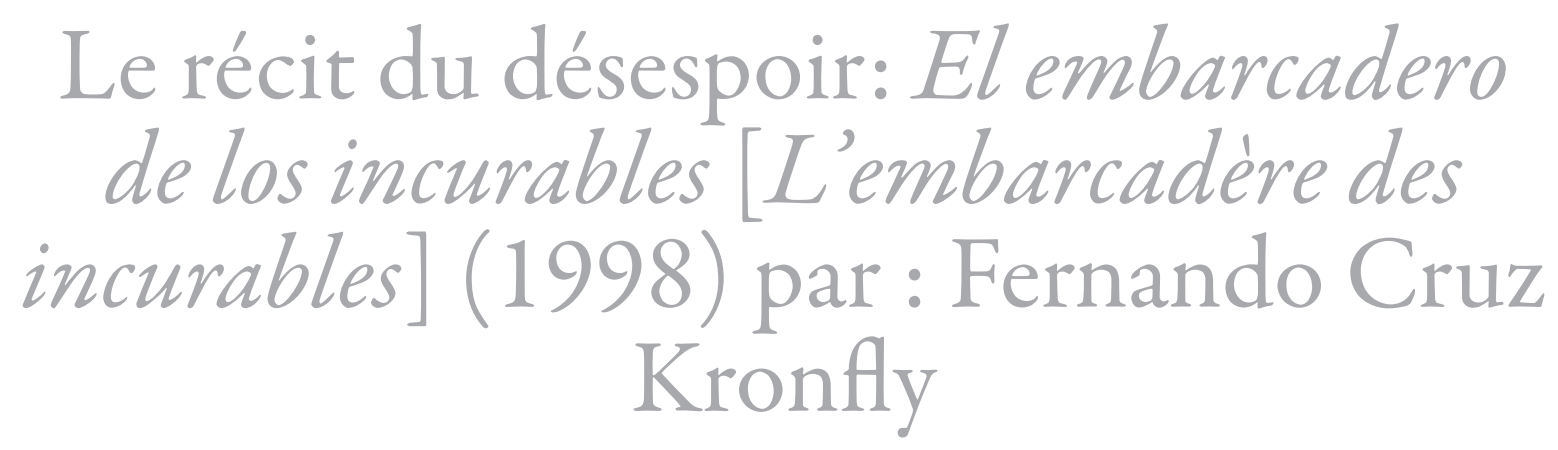

\section{Résumé}

Avant d'entrer dans certains détails du roman El embarcadero de los incurables [L'embarcadère des incurables] (1998), à travers le problème du désespoir, cet article vise, tout d'abord, à articuler ce roman dans une tradition narrative et, ensuite, à le placer dans l'ensemble de l'œuvre de Fernando Cruz Kronfly. En termes généraux, le problème et son expression romanesque sont compris comme une évaluation esthétique de la crise de la modernité et ses valeurs, et comme une prise de position face aux assauts du sentiment et du mode de vie postmoderne. En guise d'exemple, en mettant l'accent sur le type de roman utilisé par l'auteur, l'analyse porte sur la condition des sujets d'aujourd'hui et son insignifiance dans les villes postmodernes.

Mots-clés: désespoir, Fernando Cruz Kronfly, roman, modernité , postmodernisme 
No es esplendor aquello que sucede en el espiritu del caminante cuando decide por dónde debe continuar su peregrinaje, casi siempre para ir a regodearse con la muerte.

(El embarcadero de los incurables)

El punto de partida de la ficción novelesca de Fernando Cruz Kronfly es la conciencia de la desesperanza: la trama de sus novelas, lejos de privilegiar la intriga y las peripecias, las debilita y se vuelca hacia el interior, se ubica donde la experiencia de vida y la subjetividad de los protagonistas se confronta con la cultura y el sentir de un momento dado. Sin excepción, al convertirlos en metáfora de la condición humana, sus personajes aparecen como síntesis, representación o evaluación artística de la sensibilidad, de los valores y del espíritu de su época. Por lo general, sus novelas se fundamentan en la trama existencial de personajes conscientes de su intranscendencia, convencidos de su fracaso y, sobre todo, de la inminencia de la muerte. En los «íncipit» de sus novelas, sus personajes enuncian su desesperanza y desencanto, sus miserias: en tanto protagonistas aparecen prisioneros de sus propios recuerdos, atrapados en los laberintos de la memoria, alucinan, deliran y en su trasegar expresan su propia agonía. Desengañados, todos experimentan sus vidas a través del filtro de la desesperanza, convencidos de que lo único que les espera es la muerte y el olvido. Para Simón Bolívar, por ejemplo, en La ceniza del Libertador, para nada sirvieron el poder y la gloria, sus batallas y grandes ideales, razón por la cual en el ocaso de su vida busca el mar para "vomitar allí sus humores y partir para siempre" (Ceniza, 1987, p. 41) ${ }^{1}$.

Los personajes de Cruz Kronfly habitan en aquello que él llama, en La caravana de Gardel, tierras de "sombras", tristes, "del crimen" (Caravana, 1998) o, en su defecto, ciudades anónimas, junglas de concreto y neón, mares de ruido, centros del vértigo y la velocidad, ámbitos regidos por códigos y convenciones culturales acumulados de todos los tiempos. Por el hecho de ubicarse en el plano puramente humano, sus universos novelescos aparecen regidos por relaciones de amor-odio, traición, desamor o simplemente de envidia. Para él, este tipo de relaciones es el resultado de procesos históricos en los cuales los seres han acumulado el sincretismo mágico-religioso premoderno, algunos valores modernos $\mathrm{y}$ ahora las modas de la nueva era posmoderna (Tierra, 1998, p. 17). Este hibridaje cultural hace que sus personajes aparezcan dominandos por terribles fuerzas psicológicas resultantes de sangrientos mitos arcaicos que subyacen en explicaciones aparentemente racionales.

La "actitud novelesca” (Girard, 1961, pp. 15-67) de Cruz Kronfly se adhiere al espíritu crítico y autocrítico moderno y, paradójicamente, pone en la mira de su intención estética la crisis "de los relatos sobre los cuales se construyó lo moderno: el relato de la Historia, del Progreso y de la Razón" (Sombrilla, 1994, p. 33). Sin ser antiprogresista o retrógrado, en su escritura, el «progreso», la «igualdad», la «libertad», la «fraternidad» y el culto de la «individualidad», entre otros valores, son confrontados hasta revelar el alto precio que la civilización occidental ha pagado por creer, de manera desmedida, en ellos. Ante el fracaso de las teorías sociales (filosóficas, históricas, sociológicas...) en sus intentos por explicar la conducta de los seres humanos, tanto en sus novelas como en sus ensayos ${ }^{2}$, Cruz Kronfly ha decidido evaluar los embates del sentir posmoderno en la cultura $\mathrm{y}$, ante todo, en

1 Por considerar que cito varias obras de Fernando Cruz Kronfly, para evitar repetir el apellido del autor y repetir fechas de edición, lo haré recurriendo a esta modalidad: la primera vez, una abreviación con una palabra clave del título, año de edición y número de página, y luego sin fecha.

2 La sombrilla planetaria (1994), La tierra que atardece (1998) y La derrota de la luz (2007). 
la conciencia: la situación del sujeto colombiano-latinoamericano de fin de siglo XX en la crisis de los mitos modernos se convierte en objeto estético de su narrativa. Se trata de un intelectual que se resiste a perder su «mayoría de edad»y a renunciar a la particular mirada que la literatura puede lanzar sobre estos problemas. Esta coherente toma de posición se observa en el rechazo tajante de la literatura de consumo y de los temas de moda (narcotráfico, sicariato, violencia sensacionalista, guerrilla, paramilitarismo, etc.) y en una desconfianza lúcida frente a las nuevas formas de fundamentalismo de la posmodernidad (Pouliquen, 2011, pp. 32-33).

\section{Viajes hacia el inte-} rior: la conciencia ante la crisis de la modernidad

Por lo general, en sus novelas, Cruz Kronfly configura un narrador omnisciente y externo, especie de autor-creador, organizador del universo ficcional (Bakthine, 2005, pp. 13-190), presente en el texto, pero ajeno a la acción. Esto le permite configurar dos tipos de distanciamientos críticos: primero, el del autor empírico que, al diferenciarse de la voz narrativa y los personajes, organiza axiológicamente el relato; y segundo, entre el narrador y los personajes. Estas tres instancias narrativas se pueden diferenciar en Falleba-Cámara ardiente, La ceniza del Libertador, La ceremonia de la soledad, El embarcadero de los incurables, La caravana de Gardel. No obstante, en su caso la omnisciencia, más que una solución formal, sintáctica o retórica para referir una historia sin compromiso histórico alguno, es una entidad de sentido que introduce una actitud intelectual, una conciencia axiológica, lúcida, al tanto de los problemas y del caos del mundo contemporáneo, cuyos valores contrastan con la moral, tendencias, sentires y discursos oficiales comúnmente aceptados. Sin confundirse con los personajes, sin asumir las características de un yo testimonial y sin limitarse a comentar la acción o a introducir problemas prosaicos de reflexión, la voz narrativa omnisciente de la novelas de Cruz Kronfly representa un modo de percibir, sentir y vivir aquello que, sin reconocerle algo de moderno a la posmodernidad, él define como la "contemporaneidad" (Tierra, p. 13). De manera particular, sin sustraerse de la vida, este punto de vista axiológico se integra a ella expresando la manera como los problemas que afectan a sus personajes también perturban su existencia.

Ante la necesidad de mirar hacia el interior, de indagar en los sentimientos que condicionan el actuar de los seres humanos y determinan la Historia, dicha omnisciencia se debilita restándole importancia a los juicios, comentarios y análisis conceptuales. Esta estrategia narrativa se consolida con el uso exacerbado del estilo indirecto libre a la manera de Flaubert: con sus respectivas diferencias, el descubrimiento flaubertino le permite a Cruz Kronfly desdibujar los límites entre la voz del narrador y el pensamiento de los personajes, dando lugar a la interiorización de las intrigas y la multiplicación de los puntos de focalización del relato. Como observa Mario Vargas Llosa, en La orgía perpetua, "la astucia consiste en haber recortado la omnisciencia del narrador; ya no lo sabe todo, tiene dudas, su poder ha disminuido tremendamente, es idéntico al de un personaje... empleado para narrar la intimidad (recuerdos, sentimientos, sensaciones, ideas) desde adentro". Al relativizar el punto de vista, el estilo indirecto libre volatiliza al narrador omnisciente hasta poner al lector en contacto con la conciencia del personaje (1978, pp. 184-185). Sin embargo, a diferencia de Flaubert, por el hecho de sentirse afectado por los mismos problemas, el narrador de Cruz Kronfly, sin eliminar la relación irónica propia del pacto novelesco, se deshace del tono sarcástico y satírico de la actitud novelesca de Flaubert y se solidariza con los personajes.

A esta característica se suman la utilización de viejos re- 
cursos como el juego de la memoria y el viaje: esta dupla inseparable aparece como elemento constitutivo de la estructura de sus relatos y se perfila no tanto como elemento composicional, sino como soporte de la axiología que las organiza. De aquí resultan estructuras narrativas contrapuntisticas no sólo de voces o puntos de focalización, sino también de tiempos y espacios: a la manera de Proust, en las novelas de Cruz Kronfly, la "memoria involuntaria" o "rememoración no consciente" (Tadié, 1971, pp. 236-292) ${ }^{3}$ enlaza una sensación del presente con un recuerdo del pasado; indirectamente, el recuerdo enriquece la percepción de la realidad presente cuando la conciencia da rienda suelta a procesos involuntarios de la mente. En Falleba-Cámara ardiente (1979), por ejemplo, el ejercicio de la memoria se convierte en viaje; el narrador deja entender que los protagonistas (Uldarico, Mariana, Pánfilo y Pensilvania) no se desplazan, que su viaje es al pasado, a sus recuerdos de infancia, la casa de la adolescencia, a las callecitas convertidas en avenidas, al barrio demolido y convertido en urbanización, a las discotecas donde bailaron, a la música, películas, libros, amores, etc.; para desplazarse basta mirar a través de una ventana. Las ciudades (Cali, entre otras) que transitan los personajes son espacios subjetivados donde alguna vez se entrecruzaron sus vidas, ciudades vividas nostálgicamente.

Esta primera novela hace evidente el deseo de abandonar la «objetividad» de las formas narrativas-naturalistas realistas, del discurso «racional» lógicamente organizado, y volcarse hacia el interior e indagar en los móviles íntimos que determinan el comportamiento humano: la memoria, las evocaciones, los recuerdos, los sueños, incluso, la locura se apoderan de la trama novelesca y la organizan privilegiando la subjetividad de los personajes. Una voz omnisciente orquesta las cuatro voces que se agolpan, chocan, contrapuntean y dejan al descubierto sus miedos, aspiraciones y deseos, sus desaforados instintos sexuales, su alegría, pero también la certeza del sinsentido. En otras, por el hecho de ser físico, vivido en el presente de la acción, el viaje implica desplazamiento por paisajes abrumadoramente bellos pero tristes, por ciudades caóticas y, a la vez, viaje al pasado, a recuerdos desordenados, a una vida fragmentada en la que memoria y olvido se disputan para revelar a los protagonistas su condición de seres vacíos, "informes" o "líquidos", como los entiende Bauman (2013). En La ceniza del Libertador, El embarcadero de los incurables, La caravana de Gardel, el viaje se convierte en metáfora de la vida, de la existencia, en búsqueda del sentido: dependiendo de la lucidez de cada protagonista, el viaje puede ser hacia la muerte y/o la nada, o un regreso mental al origen antes de la muerte, como es el caso de Uldarico en Falleba-Cámara ardiente.

De hecho, cuando se entra en El embarcadero de los incurables, como lectores, nos preguntamos ¿Quién piensa? ¿El narrador o el personaje? En una novela con elementos del tipo corriente de la conciencia, Cruz Kronfly pone al lector en contacto con lo que piensa Uldarico: de esta manera indica que la trama se ha interiorizado, que el interés del relato se concentra en el interior, en la conciencia del personaje, en sus vivencias individuales, en la intimidad de sus desencantos y desilusiones, en la manera como experimenta y verbaliza su mundo, su presente y su pasado, en la

\footnotetext{
3 Proust establece una diferencia fundamental entre «memoria voluntaria»y «memoria involuntaria». La primera es la memoria de la inteligencia, aquella que permite recordar, en términos lógicos, una selección de sensaciones del pasado, como si estuvieran presentes en el tiempo, sin tomar las sensaciones que han hecho del evento algo vivo. La segunda, memoria de los sentidos, por el contrario, es aquella que restituye el pasado a través de una sensación fortuita que puede provenir de cualquier objeto (la madelaine, por ejemplo). Esto permite sentir inmediatamente el pasado, como si sucediera de verdad, en el acto.
} 
forma como confronta los embates de una sociedad entregada al delirio de la razón instrumentalizada. A diferencia del narrador omnisciente de La caravana de Gardel, por ejemplo, al eliminar los comentarios y secuencias narrativas y descriptivas típicas del relato realista-naturalista y, sobre todo, al abandonar toda pretensión de objetividad exterior, incluso ensayística (reflexiones sobre la modernidad), en El embarcadero de los incurables Cruz Kronfly concibe una novela de corte fenoménico en la que el "yo" axiológico del personaje se constituye en origen de una evaluación del mundo y del Ser. Aquí, un «dijo»o un «pensó», sin indicación de comillas, bastan para indicar no tanto la transición de un punto de focalización a otro, sino que la subjetividad del narrador y el personaje se confunden. Tal vez con la intención de remecer al lector, el narrador no reproduce las palabras del personaje sino que adopta su perspectiva, como si se fundieran no sus psicologías, sino sus axiologías, como si desde sus respectivas intimidades asumieran actitudes afines ante los mismos fenómenos, como si los angustiaran los mismos problemas:

¡La gran alfombra del fracaso!, dijo: la certeza de que detrás de todo existe un movimiento infinito y que en consecuencia ni las piedras perduran. La sensación de que todo en el mundo ha sido puesto en circulación, que nada se sostiene por sí mismo y que antes de cualquier parpadeo todo habrá de ser hundido en la profundidad del fango. ¡La estúpida alfombra del ser y el olvido!, dijo (Embarcadero, 1998, p. 10).

¿A quién pertenece la reflexión inserta entre las dos frases exclamativas? ¿Qué distancia existe entre lo que piensa el personaje y lo que piensa el narrador? No se trata entonces de dar cuenta de la realidad objetiva, externa, sino de la "realidad" mental, interior, íntima del movimiento de la conciencia "antes o sin necesidad de que se convierta en expresión oral" (Vargas Llosa, 1978, p. 185). Antes de que adquiera la forma impuesta por la lógica racional, la causalidad lineal incapaz de dar cuenta de las motivaciones íntimas de la experiencia humana, de los móviles reales de la conducta del Ser. LaescrituradeCruz Kronfly, con todos sus rasgos estilísticos, parece aspirar a dar cuenta de esos aspectos irracionales, instintivos, inexplicables desde el punto de vista sociológico, antropológico o histórico que, a pesar de todo, perviven en el sujeto moderno y posmoderno. Junto a otras novelas que constituyen una tendencia en el "campo" (Bourdieu, 1992) de la novela colombiana, al expresar la necesidad de mirar hacia el interior, de indagar en el sentido que las cosas y los hechos adquieren en la conciencia de los individuos, las de Cruz Kronfly representan una de las alternativas más importantes de la narrativa colombiana contemporánea o del llamado «posboom $»^{4}$.

A inicios de la década del noventa, después de haber publicado Falleba-Cámara ardiente (1979). Las alabanzas y los acechos (1980). La obra del sueño (1984) La ceniza del Libertador (1987) y La ceremonia de la soledad (1992), consciente de que su vida literaria se había iniciado bajo la dictadura del realismo mágico, en "El realismo maravilloso y sus precursores en América latina”, en la conclusión, Cruz Kronfly esboza aquello que podríamos interpretar como su toma de posición frente a la "norma estética” (Mukařovský, 2000, pp. 145-174) dominante entonces en Colombia y Latinoamérica. $\mathrm{Al}$ igual que otros escritores de

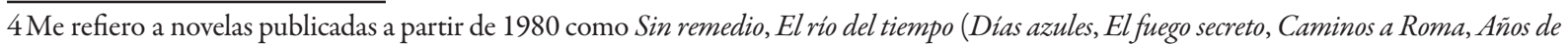
indulgencia y Entre fantasmas), La virgen de los sicarios, Primero estaba el mar, Para antes del olvido, Asuntos de un hidalgo disoluto, Señor que no conoce la luna, En el Lejero, Los ejércitos, Memorias de un hombre feliz, entre otras. Para el caso de la categoría posboom y el fenómeno literario que con ella se explica ver Roberto González Echevarría y Juan Manuel Marcos. Para el caso colombiano ver Luz Mary Giraldo. Ver referencias al final.
} 
su momento (Vallejo, Caballero, Abad Faciolince, Jaramillo Agudelo, Rosero, Tomás González, entre otros), Cruz Kronfly sintió la necesidad de marcar los deslindes de su narrativa de la del Boom fundamentada en paradigmas como "América mágica" o "América mestiza" (González, 2000). Sin dejar de reconocer que América latina había "producido una literatura de extraordinaria significación universal y se [había] abierto a espacios y mercados antes inimaginables", Cruz Kronfly declara que esa "expectativa y demanda en torno a lo «exótico» si bien daba a nuestra literatura cualidades "auténticas", al mismo tiempo, introducía "molestas connotaciones neocoloniales que ya es hora de comenzar a poner sobre las tablas con toda claridad" (Sombrilla, pp. 135-136). Según él, "el mito se [agotaba] como recurso y las leyendas indígenas acabadas de sacar del horno con su perfume de tierra reciente ya no [daban] para más". Constatar este hecho, le permite ubicar su proyecto estético en una tendencia distinta que de igual manera busca dar cuenta del "mismo hombre latinoamericano" pero inserto en las "grandes urbes" puesto que se trata de algo distinto al de la década del sesenta (p. 136):

... el gran coletazo del rea- lismo maravilloso se está extinguiendo. Hemos quedado con una tradición extraordinariamente enriquecida y valiosa. Pero es hora de comenzar a pensar en los grandes dramas del hombre de hoy. En los grandes mitos contemporáneos. En lo que, en su lenguaje, Milan Kundera denomina las grandes paradojas terminales de nuestro tiempo. La relación del hombre con la Historia y las Estructuras a las que parece pertenecer; el poder y la significación de la casualidad y del azar en medio de estas Estructuras; la significación paradojal del amor en libertad y las pérdidas irreparables que esa libertad podría arrastrar consigo. En fin, los grandes dramas y paradojas de nuestro tiempo. Ese es el reto que proponemos para la literatura posterior al realismo maravilloso. (Sombrilla, p. 137. Énfasis mío). ${ }^{5}$

Este tipo de manifiesto permite observar por qué, en su narrativa y ensayística, ha decidido evaluar la situación de los latinoamericanos en las circunstancias de aquello que él llama la "planetización", es decir, la era en que las identidades se desdibujan dando lugar a la aparición de una nueva especie que él denomina "el hombre «estándar»” (p. 136). Cruz Kronfly se ha propuesto evaluar la sociedad colombianalatinoamericana lanzada a la dinámica del consumo, del sentir posmoderno, la crisis o el fracaso de los mitos modernos, en particular, aquellos que entendieron al ser humano como un ser perfectible, capaz de constituirse en un sujeto responsable y autónomo. Cruz Kronfly encara estos problemas no de manera aislada y salpicados de cierto color local, sino en el amplio marco del sentir o del espiritu posmoderno universal. En $\mathrm{El}$ embarcadero de los incurables, sin conceptualizaciones de ningún tipo, el autor evalúa la situación del hombre contemporáneo en las urbes posmodernas, en particular, la de aquellos que se entendieron como sujetos modernos, en el sentido instituido por la Ilustración, y que ante la crisis de sus valores fundamentales toman conciencia de su desarraigo, soledad y desesperanza.

\section{La desesperanza: un mal histórico producto de la modernidad}

En tanto problema existencial convertido en objeto estético, la desesperanza no es exclu-

5 Para una explicación más amplia de la toma de posición de Fernando Cruz Kronfly en el campo de la novela colombiana y sobre todo su reacción contra el realismo mágico, ver Hélène Pouliquen, El campo de la novela en Colombia. Una introducción, en particular el acápite titulado "Otros criterios para reforzar el diseño del campo" (pp. 63-94). 
sividad de la narrativa de Cruz Kronfly. Es necesario reconocer que, tanto en la conceptualización $^{6}$ como en la ficcionalización, el escritor vallecaucano es precedido, en Colombia, por el autor de La nieve del almirante. Esto no quiere decir que la obra de Cruz Kronfly carezca de originalidad o que sea un epígono de la obra de Álvaro Mutis. Por el contrario, la recurrencia de esta problemática en sus novelas permite entender que sus personajes hacen parte de la "dolorosa familia de los lúcidos que han desechado la acción" (Mutis, 1996, p. 172); que en tanto autor, se integra a la tradición de aquellos que, de acuerdo Mutis, como Conrad, Drieu la Rochelle, Malraux, Pessoa, Musil, García Márquez, el de El coronel no tiene quien le escriba, y Malcolm Lowry han expuesto una visión desesperanzada de la vida, de la
Historia y del hombre (pp. 174180).

Cruz Kronfly se inscribe en la brecha abierta por Mutis y explota las posibilidades que ofrece la profundización en lo que éste define como "«fenomenología de la desesperanza»" (p. 180): su proyecto creador se consolida alrededor de esta idea y responde, primero, a la necesidad de conceptualizar filosóficamente sobre el asunto $y$, segundo, a algunas de las preguntas formuladas por Mutis: básicamente, “¿Por qué la desesperanza es un fenómeno contemporáneo? ¿Cuáles son los nexos entre el Romanticismo y la desesperanza?" De hecho, la desesperanza figura, como ya se dijo, como elemento estructurante de las novelas y de argumentación y reflexión de sus ensayos ${ }^{7}$.
En La tierra que atardece. Ensayo sobre la modernidad y la contemporaneidad, por ejemplo, además de incluir un ensayo titulado "La desesperanza: alto costo de la razón lúcida" (Tierra, pp. 115-132), el tema-problema atraviesa todos los ensayos. Aquí, con la intención de explicar la génesis de este fenómeno, Cruz Kronfly enriquece la reflexión ampliando el espectro explicativo. Para tal fin, sin desconocer que la literatura ha captado e interpretado de la mejor manera este problema, abandona el ámbito literario de obras y algunos autores, y se ubica en el ámbito cultural de la era moderna occidental donde, según él, es posible rastrear los orígenes de la desesperanza: para él, ésta es el resultado de unos procesos históricos culturales vividos por el hombre occidental durante la era moderna. En este mismo

6 En la conferencia dada en Ciudad de México en 1965, titulada "La desesperanza”, Álvaro Mutis expone los elementos que caracterizan el sentimiento de desesperanza y la manera como éste se manifiesta de las siguiente manera: la primera condición de la desesperanza es la de la lucidez, en una especie de relación dialéctica las dos se complementan: a mayor lucidez, mayor desesperanza y viceversa. La segunda es su incomunicabilidad, la desesperanza se convierte en la materia misma del ser, en su esencia, motivo por el cual los demás consideran al desesperanzado como un personaje alucinado, hechizado, loco, enfermo; la tercera condición es la soledad, producto de la incomunicación, de su aislamiento absoluto de los demás; la cuarta es su estrecha relación con la muerte, el desesperanzado sabe que va a morir y su existencia se convierte en una preparación serena y digna para la muerte; y, la última, quizás la más patética si se tiene en cuenta el nombre de desesperanza, es que el desesperanzado sabe que todo está perdido de antemano, que no hay esperanza posible, y sólo se interesa en sus asuntos más íntimos, las alucinaciones, los sueños y los recuerdos propios (Mutis, 1996, pp. 173-174).

7 En La sombrilla planetaria. Ensayos sobre modernidad y posmodernidad en la cultura, el tema se perfila sin enunciarse explícitamente: se adivina, por ejemplo, en el ensayo titulado "La nieve del almirante o la agonía de la modernidad (una aproximación al drama de la modernidad en la novela de Álvaro Mutis, a pesar de su insistencia en no reconocerse como un hombre moderno)” (Sombrilla, pp. 99-112); en las aproximaciones literarias compuestas entre 1977 y 1995 contenidas en Amapolas al vapor (1996) se descubre, implícitamente, en la cercanía que el autor establece con algunos autores y en el hecho de que presente el volumen afirmando que "Todo aquí ha quedado hecho y escrito, pensado y dicho contra la muerte, el terror, la amenaza diaria y el pus callejero”; y, finalmente, se hace explícito en $L a$ tierra que atardece. Ensayo sobre la modernidad y la contemporaneidad. 
libro, en "Ser contemporáneo: ese modo actual de no ser moderno" (pp. 7-45), el ensayista se autodefine como un desesperanzado (p. 42) ${ }^{8}$ y concibe la desesperanza como resultado progresivo de la secularización del pensamiento: para Cruz Kronfly el sujeto moderno, separado de los mitos mágico - religiosos y confrontado con un mundo «desencantado», es ya un desesperanzado. Razón por la cual no duda en afirmar que "de hecho, el Ideal Ilustrado condujo muy rápidamente al desencantamiento del mundo y a la desesperanza, como una de sus naturales secuelas" (p. 38). Según él, "ante la pérdida de todo fundamento" y "asaltados por la desesperanza", "quedamos delante del vacío y de su horror" (p. 43). Así, después del explicar la crisis de mitos como la igualdad, la libertad, la perfectibilidad y el progreso humano, al llegar a "La desesperanza: alto costo de la razón lúcida", para explicar "el denominado horror vacui", afirma:

Pues, separado del mito y de lo sagrado, red primordial del sentido, el hombre moderno se hunde en la desesperanza, en sensaciones de soledad y abandono, todo lo cual se traduce en una conse- cuencial pérdida del sentido de vivir. El triunfo de la razón lúcida es, entonces también el triunfo de una cierta desventura, de una cierta tristeza y desesperanza, de una cierta agonía derivada del escepticismo y del nihilismo. Y a esta apuesta por el dolor y por la desesperanza casi nadie juega, salvo contados «enfermos» éticamente comprometidos con la aventura del conocimiento a todo costo, capaces de asomarse al vacío de la duda y permanecer absortos ante su contemplación y su presencia, sin posibilidad alguna de retorno. (Tierra, p. 124)

$\mathrm{Si}$ bien la desesperanza constituye el crisol alrededor del cual se estructura la narrativa de Cruz Kronfly, sin desconocer el diálogo con Mutis, se puede observar que la particularidad del tratamiento del problema en su obra se fundamenta en una forma personal de entender la Historia y el efímero paso del hombre por la vida. A pesar de estar convencido del fracaso del proyecto ilustrado y de sus mitos, en su obra se lee la actitud y la certeza del desesperanzado, del sujeto lúcido moderno. Tal lucidez le ha permitido, sin duda, articular en su obra las grandes paradojas de la modernidad como la gloria y el poder, la miseria y el olvido humano en La ceniza del Libertador; "el declive de la fe en el amor como promesa" a causa de valores como la igualdad y la libertad, y la fragmentación del sujeto (Tierra, p. 113) en ensayos como "La congoja del amor finisecular" y en novelas como Falleba-Cámara ardiente, La ceremonia de la soledad y últimamente en La vida secreta de los perros infieles; el desarraigo en La caravana de Gardel; el deterioro humano, la vejez, la soledad y la condición urbana del transeúnte posmoderno, entre otros aspectos, en $\mathrm{El}$ embarcadero de los incurables. En todas ellas Cruz Kronfly deja claro que hoy por hoy no se puede hacer apologías de la modernidad y sus ideales, sino por el contrario observar cómo en las urbes, símbolos de la modernidad y el progreso, el ser humano ha entrado en un proceso de "licuefacción" (Bauman, 2013, p. 13) en el que poco a poco se deshumaniza.

\section{Condición de tran-} seúntes e intrascendencia en El embarcadero de los incurables

La trama de El embarcadero de los incurables se desarrolla

8 Resistiéndose a creer en una ética posmoderma que pueda hacer frente los principios de la socidad de consumo (p. 36) o al retorno a los "neomisticismos" o "neoracialismos" (p. 39), al definir la desesperanza, Cruz Kronfly no sólo plantea como "auténtica ética posmoderna" la del lúcido desesperanzado que asume la "ausencia de sentido”, el vacío y la orfandad con “entereza”, sino que al declararse hijo de la Ilustración (p. 40) se adhiere a ella entendiendola como una pérdida del sentido de lo sagrado a causa de la secularización de la cultura(p. 42). 
durante la noche de un viernes, pero no de cualquier viernes, sino uno de aquellos que en el lenguaje coloquial colombiano se denomina «viernes cultural»; es decir, la noche en que, frenéticos, un buen número de personas se entrega a la rumba, al alcohol, al cigarrillo, a las drogas, a la comida, al sexo, entre otros excesos que han entrado a formar parte de aquello que hoy se llama «cultura urbana». Como se verá más adelante, la opción por este referente temporal y cultural no es gratuito, pues a través de él se evalúa gran parte del hedonismo vulgar del sentir posmoderno en los límietes espaciales de la urbe:

Es viernes, se avizora una vigorosa subienda de peces. Todo el mundo sabe lo mucho que significa un viernes para el mundo moderno, al precipitarse la noche. El momento de la gran instalación de las mujeres, dijo, la hora de los hombres solitarios. O se enchufan, o todo está perdido para ellas. Todo lo cual no tiene nada de malo. Que se anden enchufando por el mundo resulta perfecto. Pero ocurre que luego nadie las puede desenchufar. Y cuando por fin se las logra desenchufar, se arrastran con más de la mitad del enchufe, dijo, entre alicaído y triste (Embarcadero, p. 26).
Con estas características espacio-temporales, Cruz Kronfly introduce la historia de una pareja de viejos (Uldarico y Márilin) confrontada con sus miserias personales, sus celos, su desamor, su decrepitud, sus frustraciones y deterioro físico. Así, después de cincuenta años de maltratos mutuos, un viernes al atardecer, debido a un maltrato más, Márilin decide abandonar, por fin, a Uldarico. Dejando entender que, a pesar de todo, su mujer constituía parte del hilo que aún lo ataba a la vida, perturbado, el viejo decide lanzarse a la Gran Avenida de su ciudad a buscarla: su periplo durante la noche del viernes y el amanecer del sábado constituye la trama de esta novela y, a la vez, faculta la evaluación estética de su condición de transeúnte. Como en una especie de vitrina donde observa y es observado, se exhiben las miserias de su condición, el deterioro producido por la vejez, su miedo, su anacronismo, todo su ser se expone a la crueldad de miradas frívolas y anómimas.

Por el modo como Cruz Kronfly configura sus personajes y trata los temas-problemas, se puede afirmar que su propósito es evaluar la condición del sujeto sometido a los códigos y leyes de las tan mentadas culturas urbanas: aunque desde el inicio se entiende que tanto Márilin como Uldarico son citadinos, transeúntes, se hace evidente que el viejo, a pesar de su lucidez, desconoce o ha perdido contacto con las convenciones y los imaginarios posmodernos de la ciudad. Esta particularidad hace que su relación con el espacio, la Gran Avenida, aparezca como problemática, tensa: Uldarico es representado como un ser perdido en la multitud, padeciendo la ciudad que ya no reconoce porque el «progreso» la ha transformado dejándolo sin puntos de referencia $y$ orientación no sólo espaciales, sino y ante todo identitarios, subjetivos, de seguridad, de memoria, pues ya no encuentra su ser en ella. Así, al abandonar su casa y entrar en la Avenida, las primeras evocaciones resultan melancólicas:

Sin el neón no habría posmodernidad, pensó. Las edades del mundo tuvieron sus propios tonos, se dijo [...] ¡Ah mi ciudad! Entrar en un poderoso túnel de humo $\mathrm{y}$ aullido, tibio y seguro, en el que las claves del laberinto han quedado por siempre establecidas. ¿Dónde los rostros que un día vi y ahora no veo?. (Embarcadero, p. 20)

Ajeno a toda intención descriptiva, así como desecha la posibilidad de ofrecernos una descripción o caracterización física, objetiva, del personaje, de igual manera Cruz Kronfly 
descarta la eventualidad de ofrecer al lector la descripción de la urbe como un espacio físico compuesto de casas, avenidas, puentes, rascacielos, parques $\mathrm{u}$ otros, y prefiere representarla como un espacio psíquico condicionado por el imaginario, la subjetividad y la particular manera como el personaje se ha relacionado con ella. Así, la ciudad deja de ser un simple marco-espacio en el cual se enmarca la acción y evoluciona el personaje, y se convierte en un constructo cultural que da cuenta de lo que el sujeto ha sido o querido ser, de su identidad, sus miedos, su soledad. $\mathrm{Al}$ igual que otros aspectos, la configuración del espacio se hace sin explicación conceptual o análisis sociológico alguno. La ciudad se percibe a través de los ojos del protagonista o, en su defecto, cuando el narrador interviene, su percepción expresa un problema existencial que comparten:

A todas luces la ciudad se le venía encima, lo estaba sepultando con el golpe de sus viejos mástiles y con el rigor de todos sus despojos. Una aplanadora en lo más noble de sus hombros. Uldarico lo sabía, pero a estas alturas no tenía la menor posibilidad de regreso (Embarcadero, p. 117).

El viaje de Uldarico por la Avenida más que un recorrido pictórico es un viaje al pasado, un encuentro con recuerdos, con fragmentos de lo que fue, pero también con la nada: como observa Pouliquen, dicho viaje, a la "deriva incoherente, violenta, pero humilde $y$ reflexiva", "simboliza la plena aceptación del no-sentido, de la total soledad y orfandad, marca de la nueva mayoría de edad" (Pouliquen, p. 60). La alternancia o contrapunteo entre el presente y el pasado conduce al personaje a una toma de conciencia no sólo del paso del tiempo, sino también del no-sentido de la existencia y de la intrascendencia de su ser fragmentado, pues con el paso del tiempo y el arrollador progreso de su pasado no queda nada, cuando más permanecen los objetos pero desposeídos del sentido que alguna vez tuvieron para él:

Entra por la hendija de una calle estrecha que es a sus ojos como una bisagra, paralela y émula de la Gran Avenida. Muñón ya seco en mitad del delirio del desarrollo, muñón desprendido del hacha de Robert Moses. Despejada, tranquila, familiar, vestigial. ¡Qué preciosa se observa a estas horas la tal callecita! Lugares que cree recordar de sus tiempos de niño, está viendo. Los lugares de mi constitución como hombre, dijo, de los que aún ando peregrino, una gangrena. En aquel entonces la Gran Avenida no era más que un espacioso sendero de tierra y guijarros, un pedregal en medio de hebras de hierbas y parches de sol entre grandes sombras. El viento soplaba espigas como colas de azules pájaros, cabelleras de viejos caballos. ¡Y ver lo que ahora era! El progreso se había apoderado del polvoriento sendero y sobre él había colocado lo mejor de sus signos (Embarcadero, pp. 119-120).

Para configurar el periplo y las tensiones que se establecen entra la urbe y Uldarico, objeto principal del relato, Cruz Kronfly utiliza la célebre metáfora de Heráclito «la vida es como un río»; el «todo cambia y nada permanece», «no te bañarás dos veces en el mismo río» y sobre todo la comparación entre la vida, las cosas existentes y la corriente del río organizan, en parte, axiológicamente, el relato. Dan lugar a una visión desesperanzada de la vida. Esta metáfora le permite al autor interpretar las condiciones de existencia de los colombianoslatinoamericanos de cara a los mitos premodernos, modernos y posmodernos: no se trata de una simple representación de la realidad de la vida o de las cosas, sino de un análisis literario de aquello que cambia (física y mentalmente) y de aquello que, a pesar del «progreso», permanece en el ser humano: en esencia su condición de ser 
pasional, su instinto animal. En este sentido, Cruz Kronfly desmonta el mito moderno de la perfectibilidad humana. La metáfora, que inicialmente se refiere al paso del tiempo y hace alusión al río como la vida misma, siempre en movimiento y constante cambio, se adapta al sugestivo título que alude al problema del sinsentido del mundo al que los hombres, seres "incurables", buscan otorgarle una transitoria y precaria finalidad olvidando que no pueden nada contra el olvido y la muerte.

De este modo, la Avenida corre como un río pero, lejos de expresar el progreso o cambios positivos, se ha convertido en una trampa, en algo desagradable que todo engulle y devora. Mientras que en la metáfora de Heráclito el río se encamina hacia algo más grande como el mar donde el ser se integra al todo, en El embarcadero de los incurables la Avenida-río se convierte en un "Gran Lago", pero, en comparación con la condición mortal de los seres humanos de Heráclito, el recorrido no hace un ser completo y general, sino basura. Desesperanzados, tanto el narrador como el personaje advierten que se trata de un río distinto: mientras que el primero advierte que "el río humano en que braceaba Uldarico era mucho más que un río. Largo, espeso consenso, bastante otra cosa” (p. 78), el segundo advierte que de él no resulta nada bueno, puesto que en él la vida no se abre paso:

Estoy de acuerdo, la vida debería considerarse como un río, dijo, pero ocurre que es siempre lo contrario de un río, sólo una congestionada sopa de fideos y cieno. Trapos viejos, desechos, nada se marcha jamás de nuestro lado definitivamente. ¡Ningún río, ningún río!, gritó. Todo al fin naufraga catastróficamente en medio del lodo de siempre. Huesos de vacunos, pellejos de caballares y caprinos, yo mismo lo he presenciado en las sangrantes bocas de las cachamas. Aquellos gemidos de la gente dedicada a empujar durante años animales encorvados a lo largo del viaje, dijo, penumbras pobladas de sombras de animales de carga. Y, para completar, montañas de fotografías y más fotografías acerca de semejante desgracia (Embarcadero, p. 147).

Para Uldarico no se trata de un río, sino de un "lago", razón por la cual hace constante referencia a "la metáfora del Gran Lago" proveniente del imaginario bíblico. No se puede perder de vista que, aunque desprendido de los mitos mágicos religiosos, de manera recurrente, el personaje utiliza esta imagen en el sentido metafórico configurado en el Apocalipsis (20, 9-14) para referirse al lugar donde se asiste a la «segunda muerte», donde después de la muerte, en un maremágnum de fuego y azufre, irían a sufrir eternamente los pecadores (Biblia, 2005, p. 1559). Para Uldarico "la marejada urbana" (Embarcadero, p. 141) es ya el infierno, muerto en vida ya no necesita ir a otro lugar para morir por segunda vez:

Desperdicios disueltos ya en el lago, pensó, hierba que nombra su pasado en la densidad podrida del cieno. Escamas nacaradas de pescado, jirones de tripas que rodaron de las mesas quién sabe desde cuándo, pisoteadas, dijo, cáscaras, hojas igualmente pisoteadas interminablemente. Todo por fin reunido en el estanque de las cosas perdurables. La vida jamás fue un feliz camino conducente a ningún sitio, mucho menos un río, más bien me quedo con la metáfora del Gran Lago. Heme aquí, pues, perseguido y acorralado, dijo, en poder de dos buitres y todo lo demás (Embarcadero, p. 137. Énfasis mío).

Este tipo de comentarios prefigura el final donde rendido por el cansancio, Uldarico yace en un basurero que poco a poco lo engulle. De esta 
manera, para expresar que el «perfeccionamiento» técnico no implica un "proceso de perfeccionamiento acumulativo del alma humana a lo largo de la Historia" (Tierra, p. 21), en la representación de la Avenida-río, imagen de lo que cambia, para expresar aquello que permanece, Cruz Kronfly recurre a analogías entre la humanidad y la animalidad. Uldarico evoluciona en un espacio poblado no sólo de gente descreída y blasfema (Embarcadero, p. 91), sino de gente desprovista de toda coordenada ética, de todo sentimiento de humanidad, de bondad, de solidaridad y, por el contrario, provista de todo su instinto animal. En la medida que la corriente lo arrastra, además del brillo de los carros y los gases que éstos emanan, la destrucción-construcción de edificios, de las vitrinas con objetos de moda o comidas poco apetitosas, en el frenesí del «viernes cultural», la mirada de transeúnte de Uldarico descubre, inicialmente, seres humanos convertidos por la moda en "androides" (p. 63) que poco a poco devienen en una particular fauna, en el sentido literal del término, próxima de la animalidad.

El universo ficcional de Cruz Kronfly, además de perros famélicos que comparten democráticamente la comida de los tarros de basura con sus amos (hombres-perros) recicladores (pp. 115-117), obedeciendo a la metáfora del río, se puebla de una fauna acuática depredadora o de elementos derivados de su descomposición como agallas o escamas. Así, encontramos que el viernes cultural anuncia "una vigorosa subienda de peces” ( $p$. 26); Uldarico es atacado por un par de putas con características de "sinuosos tiburones" (p. 133) o de hambrientas "cachamas" (p. 147); en su época de cabaretera Márilin recibía dinero de hombres con características de "sábalos"; y, mientras es arrastrado por la multitud, entre codazo y codazo, Uldarico cree avanzar en medio de la "pestilencia de mojarras abiertas", de "agallas por el suelo", de "avalancha de escamas nacaradas" (p. 215). Tanto el narrador como el personaje constatan que "la condición humana nunca defecciona” (111). En su absoluto desencanto, sin poder encontrarse o reconocerse en la ciudad que ha nacido y crecido, Uldarico expresará la toma de consciencia de su soledad, desarraigo y orfandad de la siguiente manera:

Me arrepiento, juro que me arrepiento. Por esta misma ruta jamás he debido volver, dijo, he quedado salpicado, de pies a cabeza atrapado de las agallas. Aquí abajo la cosa se ha puesto supremamente dura, madre, dijo, si lo vieras. Es como ver el génesis en su peor momento, dijo, de eso ni me hablen. ¡Bah! No me hagas caso, vieja, sigue durmiendo, tápate con las frazadas que en realidad nada por aquí vale la pena, vieja, dijo, uno jamás debe alejarse del centro de su telaraña a cambio de tan poco, si ya ha muerto (Embarcadero, p. 216).

De este tipo de caracterización tampoco se escapa el personaje. A pesar de su lucidez, como todo ser humano, desmitificado, desposeído de sus características de héroe, en tanto representación de lo humano, Cruz Kronfly configura a Uldarico como un ser dominado por sus instintos animales. A pesar de compartir algunos puntos de vista, la distancia crítica entre el autor-creador y el personaje se mantiene. Los ires y venires en los recuerdo de Uldarico permiten al lector adentrarse en los hábitos de un maltratador. Los maltratos mutuos dan pie para que el autor los configure como seres "ponzoñosos", provistos de "bigotes de fiera" ( $p$. 64) o de "ojos rojos de paloma" en los momentos de ira (160). De igual manera, al lanzarlo a la Avenida, advierte que "La calle se lo engullía como a un gusano" (p. 59).

En El embarcadero de los incurables la evaluación estética de la desesperanza se consolida estableciendo relaciones irónicas con autores 
cuyas obras exhiben evidentes visiones cristianas del mundo. El pensamiento secularizado de Cruz Kronfly, moderno, dialoga irónicamente, primero, con los «trascendentales del Ser» de Santo Tomás de Aquino; segundo con el pensamiento trágico de Pascal, con quien en cierta medida comparte su visión del hombre; y, tercero, con el poema Cuatro cuartetos. East Coker de T. S. Eliot. Sumados a la metáfora de Heráclito, los presupuestos de estos filósofosliteratos le otorgan al relato su densidad filosófica y lo ubican en el ámbito de la ontología, planteando el problema del ser y sus relaciones con todo lo que existe. Sin profundizar en este aspecto, a primera vista se puede decir que Cruz Kronfly entiende la ontología en su acepción moderna heideggeriana, separada de la metafísica, fenoménica y busca acercarse al ser por medio del ente que existe, que actúa, es decir, el «Ser-ahí», «Ser en el mundo»y a sus condiciones y posibilidades reales de existencia (Heidegger, 1993). La gran pregunta parece ser ¿Tienen las acciones de los seres humanos un propósito? ¿Sabe qué busca, qué se propone? ¿Puede organizar intelectualmente su actuar? $\mathrm{O}$ simplemente ¿Está sometido a la casualidad de la vida, a la rutina, a las costumbres y a la irracionalidad de sus actos?

Vale la pena, entonces, recordar que en su teoría de la «evolución embrionaria » santo Tomás plantea que en el semen ya se encuentra, virtualmente, un alma humana creada por Dios que, poco a poco, se convierte en un alma superior, sensitiva, elevada, intelectiva o racional, es decir, en persona. Según él, los «trascendentales», especie de notas, que aunque no forman parte de su esencia sí lo determinan, se encuentran en todos los seres: estos son unum, verum, bonum (uno-unidad, verdad-verdadero, buenobondad). Estas categorías le permiten exponer, primero, que el ser es uno, fundamento de la unidad, intrínsecamente no contradictorio. Segundo, en la medida que considera que el mundo y las criaturas individuales que lo habitan son la manifestación del proyecto divino, todos los seres son verdaderos puesto que cada uno de ellos expresa un proyecto, una razón de ser: sin embargo, son verdaderos según su grado de ser o de participación en el ser divino, es decir según su grado de inteligencia y voluntad. Tercero, según el santo, todo lo que es, todo ser, es bueno porque es manifestación de la bondad divina. Todo ser o ente es bueno porque, a su modo, es una perfección fruto de la voluntad divina (Santo Tomás de Aquino, 2001).

$\mathrm{Al}$ iniciar el relato y obviar el unum, el narrador da por hecho que, en las circunstancias histórico-culturales en que evoluciona Uldarico (nuestro tiempo), la unidad del ser se ha roto. Sin que sepamos aún cómo ni qué ni por qué se ha lanzado en un peregrinar por la gran Avenida de su ciudad, los pensamientos del protagonista indican al lector que en tanto ser humano está sometido a la casualidad, a la contingencia, que duda de su unidad, pero que sin embargo, debido a que en su crisis se aferra a los mitos religiosos ("su poderoso crucifijo anclado en el pecho" (Embarcadero, p. 12)), pareciera insistir en encontrar el "Verum-Bonum". No obstante, de entrada se pone en duda la posibilidad de hallarlos: "La ciudad lo engullía peor que una lombriz, sin rumbo conocido y sin orientar en ninguna forma sus pasos hacia el Verum-Bonum" (p. 10). De igual manera, convencido de su "sistemática lejanía de la Senda del Bien", Uldarico reconoce que "Los hombres no pueden jamás ser conducidos hacia el bien, dijo, sólo pueden ser llevados de la mano hacia alguna parte, hacia cualquier parte" ( $p$. 21).

Sin que el personaje se convierta en alter ego o porta voz del autor, esta última frase hace evidente cierta afinidad entre el modo de pensar del personaje y el autor creador, pues esta sanción parafrasea 
la máxima de Wittgenstein utilizada como epígrafe para determinar uno de los modos de lectura (filosófico) y establecer el código semántico de la ficción novelesca: "No es posible guiar a los hombres hacia lo bueno; sólo es posible guiarlos a algún lugar”. La lucidez del narrador y de Uldarico crea la tensión novelesca y permite entender el conflicto del ser humano desesperanzado. Uldarico sabe que no existe solución o remedio a su problema existencial: es consciente de que su periplo por la ciudad solo confirma su soledad, su desarraigo, su condición de transeúnte, su vacío, su hastío, su intrascendencia, pero al mismo tiempo descubre la tendencia del "incurable" ser humano a olvidar su naturaleza mortal y a buscar paliativos para aferrarse a la existencia, para darle sentido y en muchas ocasiones pretender inmortalizarse:

Reina cierto pavor en medio de lo más simple, dijo. Miedo a reconocer que estamos hundidos en los dominios de la casualidad. De la muerte se sabe todo pero aun así no se conoce lo mínimo, dijo. Se caer en los abismos de la primera comunión, pero eso tampoco sirve de nada, pues con los días se hunde uno de nuevo en la tristeza. ¿Quién se responsabiliza ante el rostro de los hombres de haber soltado dentro del pecho esa rata blanca que todo lo mordisquea? El olvido del ser, dijo, el lama se apodera de la pobre materia que somos. Las ventanas clavadas y la rata engordando bajo los crespones a causa del chantaje y del miedo. No hay nada más horrible que el alma, dijo, nada más paralizante, hace de nosotros lo que se le antoja. Y mientras tanto los ojos entregados a su ficción interminable (Embarcadero, p. 21).

Este modo de empezar el relato afirma la relación irónica con la Suma teológica e invalida, primero, la metafísica del ser a la manera de santo Tomás (escolástica), pone en duda la fusión entre filosofía y teología para explicar el verum-bonum del ser humano y, segundo, al mismo tiempo, pone en la mira de sus cuestionamientos la impotencia de la ética y los mitos modernos (libertad, igualdad, fraternidad, tolerancia) para corregir la naturaleza instintiva y animal del ser humano. Muy pronto el lector aprehende que Uldarico es un desesperanzado de vieja data pero que la partida de Márilin y su periplo por la Avenida lo ratifican en su visión desesperanzada de la vida:

Toda desilusión resulta proporcional a las ilusiones, dijo, la desesperanza anda suelta. Para el caso no es preciso filosofar en demasía. El hastío bebe a solas de su milenaria cerveza pera la final la relación paga, dijo, y paga caro. Hasta que uno descubre que nada vale la pena. $\mathrm{Ni}$ siquiera su sueño junto a ella, dijo, el lamentable reposo en la hondonada de su silencio. (Embarcadero, p. 29. Énfasis mío).

El diálogo con Pascal debe buscarse no de manera referencial a través de su nombre o de unos de sus pensamientos, sino a través de la ideas. No basta entonces observar cómo, en su divagar, Uldarico lo trae a colación para constatar lo que ya sabía y expresar su desesperanza. Si bien éste afirma que "La vida es por completo y para siempre una exhalación, dijo. ¡Ah mi Pascal! Dos o tres cafeterías apagadas, ni siquiera un alma. No somos más que una débil caña, dijo, incluso en el más afortunado de los casos" (p. 121), es preciso advertir la manera como, desde el punto de vista del narrador y el autor, el pensamiento del autor francés contribuye a montar el andamiaje axiológico del texto:

¡Ser tan sólo un papel!, pensó. Así era como Uldarico se veía a sí mismo. Y así era como veía a los demás. Sentía que no tenía ser, pues el ser que era jamás conseguía condensar en nada concreto. Salvo un inasible proceso de modificaciones continuas, devenir de jugadas y de tomas 
de riesgo cuyo control parecía estar fuera de sus manos. Por esa razón había terminado adorando la ontología. Ella le susurraba de lo que él ya no era. Sabía que jugaba, que aún podría desencadenar fulgurantes instantes en la partida, por efímeros que fueran. Pero él sabía que al jugar era al mismo tiempo jugado. Anzuelo y lombriz (Embarcadero, p. 37).

El diálogo con Pascal es amplioy dehecho menos irónico pues, como ya se dijo, aunque se elimine la visión cristiana del mundo (mundo creado por Dios cristiano y el hombre como fruto del pecado original en el pensamiento pascaliano), fuera de lugar en un espíritu moderno que ha eliminado todo matiz mágico-religioso, Cruz Kronfly retiene la visión de la naturaleza humana y la condición trágica del hombre: al hacer de Uldarico un lector de Pascal se retiene la idea de la fragilidad y la insignificancia del ser humano y la de la imposibilidad de que éste pueda redimirse o salvarse haciendo buenas obras, orientándose estoicamente hacia el bien. Tanto para el narrador como para el personaje, el ser humano es una "lombriz", un "gusano", un "monstruo", un ser incorregible e «incurable».

El diálogo con el poema de Eliot precisa ser entendido en la misma perspectiva y no se debe limitar a ver un ingenuo acto intertextual expresado hacia el final del relato (a partir del capítulo treinta y tres donde se dice que Uldarico leía "los Cuartetos de Eliot" sin entenderlos y por presumir ( $p$. 193)), sino como un complejo diálogo, ambivalente, pues si bien se comparten algunos temas como la existencia en el tiempo y la posibilidad de trascenderlo, su fugacidad, el trastorno provocado por el hombre en la naturaleza, la imposibilidad de explicar racionalmente o científicamente la realidad, la falta de madurez del ser humano y su incapacidad para aprovechar de su experiencia y no repetir los mismos errores del pasado y, directamente relacionado con esta último aspecto, el cuestionamiento del mito del progreso, se rechaza el toque esperanzador expresado en la posibilidad de la purificación en la oración y la integridad humana en la etapa de la vejez. Tal como se establece en los casos anteriores,
Cruz Kronfly hace caso omiso de la visión cristiana de Mundo (caída de Adán, pecado original, la redención en Cristo para superar nuestras debilidades humanas) configurada en East Coker. Ni el autor ni el narrador ni el personaje parecen creer que la humanidad pueda encontrar la salvación a través de la búsqueda de lo divino. No obstante, es necesario aclarar que conserva la ironía, el evidente desasosiego y el tono melancólico.

Los versos "En mi comienzo está mi fin”, "En mi fin está mi comienzo" ("In my beginning is my end", "In my end is my beginning") de Eliot, le permiten a Cruz Kronfly organizar, irónicamente, en estrecha relación con la metáfora del río y el viaje, el regreso al lugar de origen. La circularidad de la idea, como en una especie de eterno retorno, le permite dejar entender que Uldarico, y por ende el género humano, tiene su origen en un basurero, motivo por el cual termina, más muerto que vivo, en un basurero. De igual modo, los versos de la primera estrofa ${ }^{9}$ le permiten plantear las tensiones entre el sujeto y la urbe, es decir el problema del olvido y la dialéctica de la construcción-desconstrucción de las urbes mo-

\footnotetext{
9 En mi principio está mi fin. Una tras otra/ Las casas se levantan y se derrumban,/ Se desmoronan, las amplían,/ Las trasladan, las demuelen, las restauran, o queda en su lugar/ Un campo raso, una fábrica o una desviación./ Viejas piedras para nuevos edificios, vieja leña para nuevas hogueras,/ Viejas hogueras para la ceniza y ceniza para la tierra/ Que ya es carne, pieles y heces, / Huesos de humanos y animales, tallos y hojas de cereal./ Las casas viven y mueren: Hay un tiempo para la construcción,/ Y un tiempo para habitar y engendrar/ Y un tiempo para que el viento arranque el cristal desprendido,/ Y sacuda la tarima en que trota el ratón de campo/ Y el tapiz en jirones donde se halla bordado un lema silencioso.
} 
dernas. La ironía fundamental de El embarcadero de los incurables consiste en que, a pesar de su lucidez, contrario a lo que sucede con el poeta, el viejo Uldarico no ha madurado y piensa que es imposible renovarse. Si bien se acepta que "La tierra entera es nuestro hospital" ( $p$. 199), donde se viene a morir, en el universo de Uldarico ningún Dios viene a ofrecer su paternal cuidado ni a apartarlo del mal. Por el contrario lo abandona ${ }^{10}$.

En la misma perspectiva se inscribe la idea del "viernes" santo del poema de Eliot. Cuando esta idea aparece hacia al final del relato, cobra sentido la reiteración del "viernes" y del porqué se ubica la acción durante la noche de un «viernes cultural». Como bien lo indica la metáfora de la Avenida-río, los tiempos han cambiado y el "viernes" ya no tiene nada de santo ni de salvador: al entender, por fin, el sentido religioso del poema de Eliot, en su paráfrasis, Uldarico invalida el sacrifico de Jesucristo y, por ende la esperanza, las posibilidades de la redención para los humanos: “«... La sangre goteante, nuestra única bebida, la carne sangrienta, nuestro único alimento, a pesar de lo cual nos gusta creer que somos carne y sangre sana y sustancial - una vez más, a pesar de eso, llamamos santo a ese viernes...»" $(218)^{11}$. Sin nostalgia, pero sí con extrañeza, irónicamente, Uldarico observa que en vez de conmemorar la muerte de Jesucristo como algo positivo, el sujeto contemporáneo ha hecho de la noche del viernes un espacio y un momento para dar rienda suelta a los excesos del hedonismo posmoderno. Tal vez esto explica por qué se representa el periplo de Uldarico durante la noche de un «viernes cultural» y se considera la Avenida como "Vía estrecha, vía crucis":

Hombres y mujeres por igual se dedican a asar carne en parrillas. Vía estrecha, vía crucis. Gran humareda por el contorno, transeúntes tan codiciosos como hambrientos, la jauría humana [...] La humanidad circula lentamente, como la sangre en las arterias de los viejos mantecosos. Amanece, y la gente al clarear se viene totalmente de bruces. Algunos aún buscan sin embargo aventuras fuertes, pues a eso al parecer han bajado al corazón del infierno. La zona ya no cuenta con la alcurnia de antes. Se ven en cambio cardúmenes de entristecidas mujeres, de las sueltas y de las acompañadas, de todo en el gran género. Algunas arrastradas hasta aquella tiniebla por 1 encanto del arrabal, otras por el decadente esplendor de lugares que en otro tiempo vivieron su merecida edad de oro (Embarcadero, p. 227).

\section{Consideraciones finales}

Sin entrar en el ámbito de la filosofía pura y por el contrario manteniéndose en el plano literario de la ficción novelesca, la densidad ontológica del relato puede llevar a pensar que el autor gira alrededor del lenguaje y se aleja de la realidad objetiva, no obstante, esta tendencia hace evidente que aquello que le interesa a Cruz Kronfly de la realidad empírica es la manera como el personaje la verbaliza. De aquí que, cuando se recorrieren las primeras páginas, se pueda pensar que se entra en una especie de abstracción o en una divagación del pensamiento a la deriva, parecido al recorrido del personaje por la Avenida. Más que una narrativa embelesada en el lenguaje, en el

10 Los versos de Eliot dicen: La tierra entera un hospital/ legado por el arruinado/ millonario; el afortunado/ muere en él por el paternal/ y absoluto cuidado/ que no nos abandona y nos aparta del mal.

11 Sube el frío del pie hasta la rodilla./ Canta la fiebre en su mental alambre./ Para tener calor me enfrío a la orilla/ Del purgatorio. El frío es hielo y hambre;/ Rosa la llama; el humo, zarza, astilla./ Solo bebemos sangre, y por lo tanto/ Carne sangrante es la única comida./ A pesar de ello hacemos nuestra vida/ De suponernos carne sin espanto/ Y a este viernes llamamos Viernes Santo. 
ejercicio retórico en sí mismo, se trata de uno de los aspectos más importantes a la hora de definir su toma de posición en el campo de la novela colombiana: Cruz Kronfly deja pensar, como dice Uldarico, que ante "la ausencia moderna de todo sentido", sólo queda "el instaurado en el mundo por el lenguaje y el método" (Embarcadero, p. 49).

La importancia dada al lenguaje, a la verbalización de la realidad en la conciencia, explica su tendencia a concebir novelas de tipo fenoménico. Como para Wittgenstein, pero desplazando el problema del plano filosófico al literario de la novela, para el autor de $E l$ embarcadero de los incurables el lenguaje parece tener el poder de ordenar el mundo, de otorgarle sentido o por lo menos de ofrecer la posibilidad de asirlo: por tener lógicas similares, el lenguaje no sólo es la expresión del pensamiento, sino también una representación de la realidad: todo lo que se puede verbalizar, decir y pensar en términos significativos, lógicos, está ligado intrínsecamente a lo que existe en el mundo como realidad empírica, no sólo los objetos sino, y sobre todo, las cambiantes formas de vida y las acciones humanas ${ }^{12}$.
Si bien el propósito de Cruz Kronfly parece ser el de escudriñar en el lado oscuro, perverso si se quiere, de los mitos modernos, no se puede perder de vista el aspecto esencialmente humano que recorre su narrativa. Al entrar en la conciencia de los personajes y centrar su atención en personajes-metáforas de la condición humana que se autoconciben como yos fragmentados, el interés recae directamente no en los aspectos sociológicos, culturales $\mathrm{o}$ filosóficos, sino en las vivencias de seres consciente de que resulta imposible conectar con una tradición, de que su vida está hecha de fragmentos: Uldarico dirá "Es a toda esta horrible fragmentación y derrota a lo que llamamos Historia” (p. 48). De aquí que en esta narrativa de la desesperanza se privilegie el punto de vista de personajes que han perdido la fe en los dioses y en los mitos modernos. Abandonados de Dios y del mito del progreso humano, los personajes de Cruz Kronfly se convierten en huérfanos, en nómadas existenciales que han perdido la ilusión de encontrar en algún lugar, o estado mental, el sentido de sus vidas: se trata de seres que han caído en el vacío. De aquí la atmósfera nihilista de sus novelas, la angustia y la desesperanza de sus personajes. $\mathrm{Al}$ inscribir a Uldarico en la tradición de desesperanzados y ubicándolo en las circunstancias de las problemáticas de la contemporaneidad, el autor configura aquello que él entiende y propone como sujeto con una ética posmoderna es decir, que, a pesar de que ha entrado en un proceso de disolución, conserva la lucidez suficiente para no negociar con los nuevos sentidos dados a la modernidad.

En sus novelas nadie puede albergar algo de esperanza y aspirar a la inmortalidad o trascendencia ontológica. Esta visión común a todas sus novelas es fiel a su filiación a la desesperanza expresada en sus ensayos: entendida como un estado de ánimo que nace de la lucidez de aquellos que no pueden ya refugiarse en la magia premoderna (religiosa o pagana) o en las utopías modernas de la racionalidad instrumental de la ciencia. A Uldarico, como a Simón Bolívar y Arturo Rendón (La caravana de Gardel), no le queda más que exorcizar el vacío interior y lanzarse al río de basura y de la nada. A la hora de buscar las motivaciones antropológicas y psíquicas de los actos humanos,

12 En mi concepto la proximidad de la narrativa de Cruz Kronfly con las ideas de la lógica del lenguaje planteadas por Wittgenstein en Tractatus logico-philosophicus y luego en Investigaciones filosóficas amerita un estudio detallado. A manera de hipótesis me permito plantear que la narrativa de nuestro autor se alimenta en ella para desembocar en el tipo de novela que practica. 
Cruz Kronfly parece confiar más en las ventajas que ofrece la fusión entre literatura, psicoanálisis y filosofía que en la filosofía o la moral religiosa puras: los epígrafes tomados de pensamientos de Wittgenstein, Conrad y Shakespeare ratifican esta toma de posición y autoriza en la novela la elaboración de una especie de filosofía de los actos humanos.

\section{Referencias}

Aquino, S.T. de. (2001). Suma de teología. (Presentación de Damián Byrne O.P.). Madrid: Biblioteca de Autores Cristianos.

Bakthine, M. (2005). Estética de la creación verbal. (Trad. Tatiana Bubnova). Buenos Aires: Siglo XXI editores Argentina S.A.

Bauman, Z. (2013). Modernidad líquida. Buenos Aires: Fondo de Cultura Económica.

Bourdieu, P. (1992). Les règles de l’art. Genèse et structure du champ littéraire. Paris: Éditions du Seuil.

Cruz Kronfly, F. (1987). La ceniza del Libertador. Bogotá: Planeta.

Cruz Kronfly, F. (1994). La sombrilla planetaria. Ensayos sobre Modernidad y Posmodernidad en la cultura. Bogotá: Planeta.

Cruz Kronfly, F. (1998). El embarcadero de los incurables. Bogotá: Norma.

Cruz Kronfly, F. (1998). La caravana de Gardel. Bogotá: Planeta.

Cruz Kronfly, F. (1998). La tierra que atardece. Ensayo sobre la modernidad y la contemporaneidad. Bogotá: Planeta.

Eliot, T.S. (2014). East Coker. Aproximación y notas de José Emilio Pacheco. Letras libres, 16(181), 46-55. Recuperado el 24 de mayo de 2014 de http://www.letraslibres.com/sites/default/ files/eliot-e.pdf

Giraldo, L.M. (2007). Utopías y distopías. Del boom al postboom. Fractal, 45/46. Recuperado el 20 de mayo de 2014 de http://www.mxfractal.org/Revis taFractal45-46MaryGiraldo.html

Girard, R. (1961). Mensonge romantique et vérité romanesque. Paris: Bernard Grasset. 
González Echevarría, R. (1987). Severo Sarduy, the Boom and the Post Boom. Latín American Literary Review, 15(29), 57-71.

González Echevarría, R. (2000). Mito y archivo. Una teoría de la narrativa latinoamericana. México D.F.: Fondo de Cultura Económica.

Heidegger, M. (1993). Ser y Tiempo. Barcelona. Editorial Planeta.

Marcos, J.M. (1985). De García Márquez al post-boom. Madrid: Orígenes.

Mukařovský, J. (2000). Función, norma y valor estéticos como hechos sociales. En: J. Jandová y E. Volek (ed.). Signo, función y valor. Estética y semiótica del arte de Jan Mukaŕovský. (pp. 127203). Bogotá: Plaza y Janes, Universidad Nacional de Colombia, Universidad de Los Andes.

Mutis, Á. (1996). La desesperanza. En: La muerte del estratega. Narraciones, prosas y ensayos. (pp. 171180). México: Fondo de Cultura Económica.

Pouliquen, H. (2011). El campo de la novela en Colombia. Una introducción. Bogotá: Instituto Caro y Cuervo.

La santa biblia. Antiguo y nuevo testamentos. (2005). Bogotá: Sociedades Bíblicas Unidas.

Tadié, J-Y. (1971). Proust et le roman. Paris: Gallimard.

Vargas Llosa, M. (1978). La orgía perpetua. Barcelona: Bruguera. 